\title{
CARACTERÍSTICAS FÍSICAS DO MARACUJÁ-AZEDO EM FUNÇÃO DO GENÓTIPO E MASSA DO FRUTO ${ }^{1}$
}

\author{
CARLOS EDUARDO MAGALHÃES DOS SANTOS², CLAUDIO HORST BRUCKNER ${ }^{3}$, \\ COSME DAMIÃO CRUZ ${ }^{4}$, DALMO LOPES DE SIQUEIRA ${ }^{5}$, LEONARDO DUARTE PIMENTEL $^{6}$
}

RESUMO-Foram estudas as características físicas dos frutos de progênies de maracujazeiro-azedo e as correlações entre estas características. De uma planta de cada progênie, foram colhidos vários frutos resultantes de polinização natural, pesados e divididos em duas classes de massa do fruto (1: 180 a 230g e 2: 80 a 130 g). Posteriormente, de cada classe de massa, foram retirados 2 frutos, aleatoriamente, para serem mensuradas as características físicas: massa (g), massa da casca (g), massa de sementes (g), massa de suco (g), comprimento longitudinal ( $\mathrm{mm})$, diâmetro equatorial $(\mathrm{mm})$, espessura da casca $(\mathrm{mm})$, número de sementes, quantidade de suco por semente (g), relação entre a espessura da casca e o raio, relação entre o comprimento longitudinal e o diâmetro equatorial, rendimento de suco (\%), percentagem de casca (\%), percentagem de semente (\%) e a percentagem de resíduo (\%). A espessura da casca varia com a massa do fruto, de modo que a avaliação da espessura da casca em frutos de diferentes massas pode provocar equívocos na avaliação de progênies. Termos para indexação: Passiflora edulis, seleção, qualidade do fruto.

\section{PASSION FRUIT PHYSICAL TRAITS IN FUNCTION OF THE GENOTYPES AND FRUIT WEIGHT}

\begin{abstract}
Physical traits of the fruits of several progenies were evaluated and the correlations among them were studied. The fruits, originated of natural pollination, were picked up at the harvest stage and classified in two weight classes: 1 - 180 to $230 \mathrm{~g}$ and 2 - 80 to $130 \mathrm{~g}$. Of each class were sampled two fruits to evaluate the mass of the fruit (g), mass of the skin (g), mass of the seeds (g), mass of the juice (g), longitudinal length and equatorial diameter of the fruit ( $\mathrm{mm})$, thickness of the skin $(\mathrm{mm})$, number of seeds, juice weight per seed (g), ratio skin thickness/ fruit ray, ratio longitudinal length/equatorial diameter, juice content (\%), skin ratio (\%), seed ratio (\%) and residues (\%). The thickness of the skin varied among the mass classes, indicating that skin evaluation of different fruit sizes can lead to misunderstandings and the evaluation of the progenies.
\end{abstract}

Index terms: Passiflora edulis, selection, fruit quality

\section{INTRODUÇÃO}

O maracujá-azedo (Passiflora edulis Sims), originário da América tropical, é cultivado em todo o território nacional (Bruckner et al., 2002), devido à apreciação por seus frutos. É comercializado tanto in natura como na forma de produtos industrializados (Ataíde et al., 2006).

O Brasil é o primeiro produtor mundial de maracujá, sendo que, no ano de 2005, a produção brasileira foi de $479.813 \mathrm{t}$, com rendimento médio de 13.395 kg/ha (Agrianual, 2008).
O melhoramento genético do maracujazeiro já trouxe avanços significativos em relação ao incremento da produtividade, melhoria da qualidade de frutos e busca de genótipos resistentes ou tolerantes a doenças e pragas importantes na cultura (Bruckner et al., 2002; Gonçalves et al., 2007; Santos et al., 2008).

No tocante ao maracujá in natura, os consumidores, em geral, preferem frutos maiores, de aparência atraente e com elevada quantidade em suco. Na indústria de suco, há preferência por frutos de alto rendimento em suco, maior acidez e com maior teor de sólidos solúveis totais (Nascimento

\footnotetext{
${ }^{1}$ (Trabalho 274-08). Recebido em: 07-11-2008. Aceito para publicação em: 07-04-2009. Parte da tese do primeiro autor apresentada à Universidade Federal de Viçosa, para a obtenção do grau de "Doctor Scientiae”. Trabalho desenvolvido com apoio financeiro da CAPES, CNPq e FAPEMIG.

${ }^{2}$ Eng. Agr. DSc. Professor - Campus de Rio Paranaíba - Universidade Federal de Viçosa - 38810-000. E-mail: carlos.magalhaes@ ufv.br

${ }^{3}$ Eng. Agr., DSc., Professor - Fruticultura/DFT - Universidade Federal de Viçosa - 36570-000. E-mail: bruckner@ufv.br; siqueira@ufv.br.

${ }^{4}$ Eng. Agr., DSc., Professor - Biologia Geral/DBG - Universidade Federal de Viçosa - 36570-000. E-mail: cdcruz@ufv.br.

${ }^{5}$ Eng. Agr., MSc., Doutorando em Fitotecnia - Fruticultura/DFT - Universidade Federal de Viçosa - 36570-000. E-mail: agropimentel@yahoo.com.br.
} 
et al., 1999).

Diversos pesquisadores relatam que o rendimento de suco do maracujazeiro-amarelo varia entre 26 a 31,5\% em relação ao peso do fruto (Sjostrom \& Rosa, 1977; Lipitoa \& Robertson, 1977). Entretanto, outros autores relatam variações no rendimento de suco em decorrência da época de produção (Nascimento et al., 1999), grau de maturação (Araújo et al., 1974; Aular et al., 2000) e variedades cultivadas (Farias et al., 2005).

A seleção de fenótipos superiores, sejam indivíduos ou famílias, é uma prática de considerável importância para o melhorista, uma vez que a obtenção de populações melhoradas passa pela seleção e recombinação de indivíduos ou famílias (Bruckner et al., 2002). A seleção necessita ser feita simultaneamente para vários caracteres, por vezes correlacionados entre si positivamente, como diâmetro equatorial e massa do fruto (Negreiros et al., 2007), ou negativamente, como número de frutos por planta e massa dos frutos (Pimentel et al., 2008).

Visando a subsidiar os procedimentos de seleção, objetivou-se neste trabalho promover o estudo das características físicas dos frutos de progênies de maracujazeiro-azedo e as correlações existentes entre estas características.

\section{MATERIAL E MÉTODOS}

O trabalho foi desenvolvido no Departamento de Fitotecnia, da Universidade Federal de Viçosa, analisando-se vinte progênies de meios-irmãos de maracujazeiro-azedo.

As plantas estavam dispostas no campo, no espaçamento de 3,0 m entre fileiras e 3,5 m entre plantas, totalizando 950 plantas/ha. A condução das plantas foi feita em espaldeira vertical com 1,80 m de altura em fio galvanizado número 12 , sendo realizados todos os tratos culturais normalmente recomendados à cultura.

Nesta população, formada por 75 progênies, selecionaram-se as 20 progênies e, de cada progênie, a planta com vigor vegetativo e reprodutivo superior às demais, constituindo um genótipo avaliado de cada progênie. De cada planta, foram colhidos vários frutos resultantes de polinização natural, encaminhados ao Laboratório de Análise de Frutas do Departamento de Fitotecnia, onde foram pesados e divididos em duas classes de massa do fruto $(1 \rightarrow 180$ a $230 \mathrm{~g}$ e $2 \rightarrow 80$ a 130 g). De cada classe, retiraram-se dois frutos, aleatoriamente, nos quais foram mensuradas as características físicas: massa (g), massa da casca (g), massa de sementes (g), massa de suco (g), comprimento longitudinal (mm), diâmetro equatorial (mm), espessura da casca (mm), número de sementes, massa de suco por semente (g), relação entre a espessura da casca e o raio, relação entre o comprimento longitudinal e o diâmetro equatorial, rendimento de suco (\%), percentagem de casca (\%), percentagem de semente (\%) e a percentagem de resíduo (\%).

Nas determinações métricas, utilizou-se paquímetro digital, com precisão de $0,01 \mathrm{~mm}$, e as massas foram obtidas com auxílio de balança eletrônica de $0,01 \mathrm{~g}$ de precisão. A espessura da casca foi medida na região equatorial do fruto. $\mathrm{O}$ suco foi obtido, batendo-se a polpa no liquidificador, com hélice protegida por fita adesiva, de forma intermitente, sem danificar as sementes, passando em seguida por peneira de malha fina. Posteriormente, determinaram-se a massa do suco e o rendimento de suco, que foram determinados pelo coeficiente entre a massa do suco e a do fruto, expresso em porcentagem. As sementes, depois de separadas da polpa, foram contadas manualmente. A percentagem de casca do fruto, percentagem de semente por fruto e resíduo (impurezas que sobram após a extração do suco), foi determinada pelo coeficiente entre as massas destas variáveis e a do fruto. A relação massa de suco por semente foi obtida pelo coeficiente entre a massa de suco por fruto e o número de sementes presentes no fruto. A relação espessura de casca/raio do fruto foi obtida por relação direta, sendo o raio a metade do diâmetro equatorial, e a relação comprimento longitudinal/diâmetro equatorial foram obtidas pela relação direta entre as duas características.

Foi realizada correlação simples (Pearson) entre as variáveis analisadas. A estimação do coeficiente de correlação fenotípico $\left(r_{f}\right)$ entre dois caracteres, $X$ e $Y$, foi realizada de acordo com Cruz et al. (2004).

O experimento foi instalado segundo um esquema de parcelas subdivididas, tendo nas parcelas as progênies e, nas subparcelas, as classes de massa do fruto (1 e 2). O delineamento utilizado foi o inteiramente casualizados, com 2 repetições e um fruto por unidade experimental. Os dados referentes a percentagens sofreram transformação $\mathrm{em}, \operatorname{arcsen} \sqrt{\frac{\mathrm{x}}{100}}$, e o referente ao número de sementes em $\sqrt{x}$, posteriormente foram submetidos à análise pelo aplicativo computacional GENES (Cruz, 2001), versão 2006, como também a estimação dos coeficientes de correlação. 


\section{RESULTADOS E DISCUSSÃO}

Para todas as características, com exceção da massa média do fruto, verificaram-se diferenças significativas $(\mathrm{P}<0,01)$ entre as médias das progênies estudadas, evidenciando a ocorrência de variabilidade nessa população (Tabela 1). Faleiro et al. (2005) relataram que o maracujazeiro é uma planta com ampla variabilidade genética, a qual deve ser convenientemente utilizada em programas de melhoramento genético. Santos et al. (2008) evidenciam que a ocorrência de variabilidade é condição essencial para o estabelecimento de um programa de melhoramento genético e deve ser explorada com vistas a melhorias nas qualidades do fruto.

A massa fresca do fruto não diferiu significativamente entre as progênies, mas diferiu $(\mathrm{P}<0,01)$ entre as classes, demonstrando a eficácia da padronização prévia dos frutos em classes de massa fresca.

Quanto ao comprimento longitudinal (COM), diâmetro equatorial do fruto (DIAM) e relação entre o comprimento longitudinal/diâmetro equatorial (COD), observaram-se diferenças significativas $(\mathrm{P}<0,01)$ entre as progênies, demonstrando a ocorrência de variabilidade entre as progênies quanto à forma dos frutos. Em relação às classes de massa, houve diferenças entre elas no tocante à COM e DIAM, mas não à COD (Tabela 1), indicando que a forma do fruto não foi influenciada pela sua massa.

Akamine et al. (1974) recomendam a seleção de plantas com frutos de forma ovalada por, supostamente, apresentarem maior teor de suco; entretanto, Negreiros et al. (2007) observaram, em estudo sobre correlações entre as características físicas do maracujazeiro-azedo, que o rendimento de polpa não possui correlação com a forma redonda ou ovalada do fruto.

A massa fresca da casca dos frutos (MCAS) foi influenciada pelas progênies, pelas classes de massa e apresentou interação entre os fatores, demonstrando que as progênies possuem comportamentos distintos quanto à massa fresca da casca nas duas classes de massa analisadas (Tabela 1). Os resultados demonstram que a maior percentagem de casca foi observada nos frutos da classe 2 (50,27\%), nos quais metade da massa fresca do fruto é composta por casca, enquanto nos frutos pertencentes à classe 1 , esse valor foi de 44,05\%. Aular et al. (2000) relatam que a maior percentagem de casca do fruto em relação à massa fresca é obtida aos 53 dias, quando ainda se encontram em inicio do desenvolvimento; posteriormente, esta proporção tende a reduzir-se. Pelos dados deste trabalho, verificou-se que a percentagem de casca é variável com o tamanho de fruto amostrado, no ponto de colheita. Os resultados indicam que, mesmo para a indústria, devem-se selecionar plantas com frutos maiores, que terão menores percentagens de casca.

$\mathrm{Na}$ espessura da casca (ECAS), ocorreram diferenças significativas entre as progênies, o que demonstra ainda haver variabilidade entre as progênies, apesar de serem progênies obtidas de ciclos de seleção visando à redução na espessura da casca. Entretanto, ocorreram diferenças significativas $(\mathrm{P}<0,05)$ entre as classes de frutos, demonstrando que frutos da classe 2 apresentam menores valores de espessura da casca. Este resultado indica que a espessura é variável com o tamanho do fruto, o que deve ser considerado na avaliação de frutos, para assegurar o adequado progresso genético.

Desta maneira, os programas de melhoramento do maracujazeiro devem atentar para o fato de padronização do tamanho do fruto para avaliar a espessura de casca, evitando selecionar progênies que produzam frutos de massa reduzida com base na seleção para menor espessura de cascas. Alternativamente, pode buscar-se a avaliação da espessura da casca por alguma relação com outra característica que anule o efeito da massa ou o tamanho do fruto na espessura da casca.

Quanto à relação entre a espessura da casca e o raio equatorial do fruto (ECR), observaram-se diferenças entre progênies e entre as classes de massa. Como a ECR difere entre as classes, ela não é adequada como padronização da avaliação da espessura da casca.

O híbrido IAC-277, avaliado por Batista et al. (2005), apresentou espessura média de casca de $4,79 \mathrm{~mm}$. No presente estudo, as progênies avaliadas apresentaram espessuras em média de 3,54 $\mathrm{mm}$ e 3,24 mm para frutos pertencentes às classes 1 e 2, respectivamente, revelando que a seleção ao longo do tempo para está característica está sendo eficiente.

Viana et al. (2004), estudando populações de maracujazeiro-azedo propagadas vegetativamente e cultivadas em dois ambientes, não verificaram diferenças entre os ambientes para a espessura da casca, sendo que esta apresentou valores de 3,69 e 3,59 mm, nos ambientes de Macaé-RJ e Campos dos Goytacazes-RJ, respectivamente.

A massa de suco apresentou diferenças significativas entre progênies e entre as classes de massa do fruto, demonstrando que frutos da classe 1 apresentam maiores quantidades de suco. De forma semelhante, o rendimento de suco, em percentagem, foi maior nos frutos da classe 1, que apresentou rendimento de $35,83 \%$, enquanto na classe 2 o rendimento foi de 32,38\% (Tabela 1). O rendimento 
médio de suco foi na mesma faixa e superior aos padrões recomendados para a indústria, que deve estar entre 30 e 33\% (Haendler, 1965). Entretanto, Batista et al. (2005) encontraram valores maiores de rendimento em diversas seleções analisadas, com valores em torno de $40 \%$. O rendimento médio de suco encontrado neste trabalho foi semelhante ao encontrado por Viana et al. (2004), que foi de $34,58 \%$. A diferença no rendimento de suco entre as classes de massa, superior a $3 \%$, indica que a seleção de frutos maiores atende também às necessidades da indústria, conforme já discutido anteriormente.

A percentagem de resíduo por fruto apresentou diferenças $(P<0,01)$ entre progênies e entre as classes de massa. Os frutos pertencentes à classe 1 apresentaram maior rendimento em suco, mas também maior percentagem de resíduo, o qual se constituiu em $15,77 \%$ da massa total do fruto. Contribui para o maior rendimento de suco a menor percentagem de casca dos frutos de classe 1 (Tabela 1). Lipitoa \& Robertson (1977) consideram o resíduo, todas as sobras resultantes da extração do suco, incluídas nestas as sementes, e os valores oscilaram entre $19-20 \%$ da massa total do fruto. No presente estudo, ao proceder à soma da percentagem de resíduo com a de semente, encontram-se valores de 20,1 e $17,34 \%$, para frutos das classes 1 e 2 , respectivamente.

Quanto à quantidade de suco por semente, ocorreram diferenças entre as progênies $(P<0,01)$ e entre as classes $(\mathrm{P}<0,05)$. A classe 2 apresentou maior quantidade de suco por semente. Pode-se inferir que, em decorrência de frutos da classe 2 apresentarem menor quantidade de sementes que frutos da classe 1 , os mesmos tiveram maior relação fonte-dreno, armazenando maior quantidade de suco em cada semente.

A massa de suco por semente desperta interesse em ser incorporada nas avaliações realizadas no programa de melhoramento do maracujazeiro, pois a seleção de genótipos com maior massa de suco por semente, indiretamente, resultaria na seleção para rendimento superior em suco. Como o número de sementes, a massa do fruto e o rendimento de suco são correlacionados com a quantidade de pólen na polinização (Akamine \& Girolami, 1959), a seleção de genótipos com maior massa de suco por semente poderá, eventualmente, contribuir para maior rendimento de suco em condições de polinização deficiente. A quantificação da massa de suco por semente, contudo, apresenta o inconveniente de poder ficar suco aderido à peneira que se utiliza na extração, ocasionando erros de mensuração. Desta maneira, há necessidade de aprofundar os conheci- mentos a respeito da viabilidade da avaliação desta característica.

Quanto à massa de sementes, número de sementes, massa unitária de sementes e percentagem de sementes por fruto (Tabela 1), verificaram-se diferenças significativas $(\mathrm{P}<0,01)$ entre as progênies e entre as classes de massa, exceto na massa unitária de semente entre classes. Houve interação entre os fatores para a massa fresca das sementes; desta forma, as progênies estudadas apresentam comportamento diferenciado quanto à massa de sementes em cada classe de massa do fruto. Assim, dentro da mesma classe de massa, há progênies que apresentam elevada massa de semente, em contradição a outras com reduzida massa. O efeito significativo entre progênies para massa unitária de sementes indica efeito do genótipo nessa característica. Alexandre et al. (2004) verificaram efeito do genótipo na germinação e velocidade de emergência.

A massa fresca das sementes foi consequência do número de sementes, que também variou entre progênies e entre as classes, uma vez que a massa unitária das sementes não diferiu entre as classes, embora tenha havido diferenças entre as progênies.

O número médio de sementes por fruto foi de 371,8 e 171,4 nas classes 1 e 2, respectivamente. Nascimento et al. (2003) observaram a média de 281 sementes por fruto, estando superior aos resultados encontrados por Nascimento et al. (1999), Meletti et al. (1992) e Senter et al. (1993), com 248; 180 e 118 sementes por fruto, respectivamente.

As sementes representam menos que $5 \%$ da massa fresca total do fruto, corroborando os resultados obtidos por Carvalho et al. (2000), que encontraram valor de 5,5\% de sementes.

Akamine \& Girolami (1957) relatam a existência de correlação positiva entre o número de sementes por fruto e a quantidade de suco; deste modo, maiores quantidades de sementes tendem a proporcionar maiores rendimentos de suco. Pelos dados do presente trabalho, embora frutos maiores e com maior número de sementes tenham maior rendimento em suco, a massa de suco por semente foi menor em frutos com maior quantidade de sementes.

Quanto às correlações $\left(\mathrm{r}_{\mathrm{f}}\right)$ existentes entre as características (Tabela 2), percebe-se que a correlação de maior magnitude foi entre a massa fresca de sementes e o número de sementes por fruto $\left(r_{f}=0,963\right)$. O número de sementes foi diretamente proporcional à massa fresca das sementes, uma vez que não houve diferenças significativas entre a massa unitária das sementes e a massa fresca das sementes. Observou-se que o diâmetro equatorial promove maior influência sobre a massa fresca do fruto $\left(r_{f}=\right.$ 
$0,904)$ que o comprimento longitudinal $\left(r_{f}=0,790\right)$, e que a massa do fruto apresentou correlação significativa com massa fresca da casca $\left(r_{f}=0,853\right)$, massa fresca do suco $\left(r_{f}=0,889\right)$, massa fresca de sementes $\left(r_{\mathrm{f}}=0,886\right)$ e número de sementes $\left(\mathrm{r}_{\mathrm{f}}=0,814\right)$, e de menor magnitude com o rendimento em suco $\left(r_{\mathrm{f}}=\right.$ $0,285)$ e percentagem de resíduo $\left(r_{\mathrm{f}}=0,348\right)$. A massa fresca do fruto é composta por massa fresca do suco, da casca, da semente e de resíduos; contudo, pelos valores observados, admite-se que a massa fresca do suco influenciou mais na massa fresca do fruto.

Estes resultados estão de acordo com os observados por Negreiros et al. (2007), que, em estudos sobre correlações entre as características de maracujá, observaram que a massa da polpa (suco + sementes) promove maior influência na massa fresca do fruto, do que a massa da casca. Além do mais, o peso da polpa é mais importante comercialmente que o peso da casca (Albuquerque et al., 2002).

Ocorreram correlações significativas, porém inversas, entre a massa fresca do fruto e a percentagem de casca e a quantidade de suco por semente. Fica evidenciado, desta forma, que frutos com elevada massa apresentam menor proporção de casca, o que é interessante para o melhoramento. A menor quantidade de suco por semente, em decorrência do aumento no número de sementes, é confirmada pela correlação inversamente proporcional entre o número de sementes e a quantidade de suco por semente. Porém, o aumento no número de sementes no fruto resulta em maior rendimento de suco.

Akamine \& Girolami (1957) observaram que um maior número de sementes corresponde a maior comprimento, diâmetro, massa de frutos e porcentagem de suco por fruto.

Ferreira et al. (1975) encontraram correlações fenotípicas altas e positivas entre o peso do fruto e o comprimento e diâmetro dos frutos do maracujá-amarelo, com valores de correlação de 0,8069 e 0,8796, respectivamente. Os autores também encontraram correlações fenotípicas altas e positivas entre o peso de polpa mais semente e o comprimento e diâmetro do fruto, com coeficientes de correlação de 0,6785 e 0,7671 , respectivamente, assim como maior correlação entre o diâmetro do fruto com o volume de suco, ou seja, frutos com maior diâmetro equatorial apresentam maior peso de fruto, maior quantidade de polpa e maior volume de suco. Os resultados encontrados por Ferreira et al. (1975) estão de acordo com os deste trabalho, além de estarem corroborando os encontrados por Negreiros et al. (2007), que observaram que frutos com maior diâmetro equatorial apresentam maior peso de polpa, indicando que há a tendência de os frutos de maior diâmetro equatorial terem maior volume de suco.

Negreiros et al. (2007) relatam a ocorrência de correlação significativa entre o diâmetro equatorial do fruto e massa do fruto, indicando que a seleção de plantas com frutos pesados poderá ser feita diretamente no campo, partir da medição do diâmetro equatorial dos frutos, sem a necessidade de pesá-los, reduzindo os trabalhos de seleção. Pimentel et al. (2008) verificaram que a seleção para massa do fruto é eficiente no terceiro mês do primeiro ano de produção, podendo ser feita precocemente para reduzir o volume de trabalho com outras avaliações posteriores.

Ainda relacionado ao diâmetro equatorial do fruto, percebe-se correlação alta e significativa com a massa fresca de suco, semelhantemente aos resultados obtidos por Ferreira et al. (1975), que verificaram a existência de maior correlação do diâmetro com o volume de suco. Entretanto, não se verificou correlação significativa entre o diâmetro equatorial e a percentagem de suco por fruto.

O rendimento em suco, objetivo importante no processo seletivo, apresentou correlação significativa com massa fresca do fruto $\left(r_{f}=0,285\right)$, espessura de casca $\left(r_{f}=-0,464\right)$, massa fresca do suco $\left(r_{f}=0,671\right)$, massa fresca das sementes $\left(r_{\mathrm{f}}=0,340\right)$, número de sementes $\left(\mathrm{r}_{\mathrm{f}}=0,320\right)$, percentagem de casca $\left(r_{\mathrm{f}}=-0,890\right)$, percentagem de sementes $\left(r_{f}=0,292\right)$, quantidade de suco por semente $\left(r_{f}=0,313\right)$ e a relação entre a espessura da casca e o raio equatorial $\left(r_{f}=-0,508\right)$. Entre estas variáveis, destaca-se que a redução na espessura da casca promove aumentos no rendimento de suco, e aumentos na massa de suco por semente proporcionam aumento no rendimento de suco, confirmando a necessidade de analisar criteriosamente a incorporação da avaliação da massa de suco por semente nas características avaliadas no processo seletivo do maracujazeiro.

A correlação positiva entre rendimento de suco e massa fresca do fruto indica que a seleção de plantas com frutos grandes pode beneficiar tanto a produção destinada ao mercado "in natura” como à indústria. 


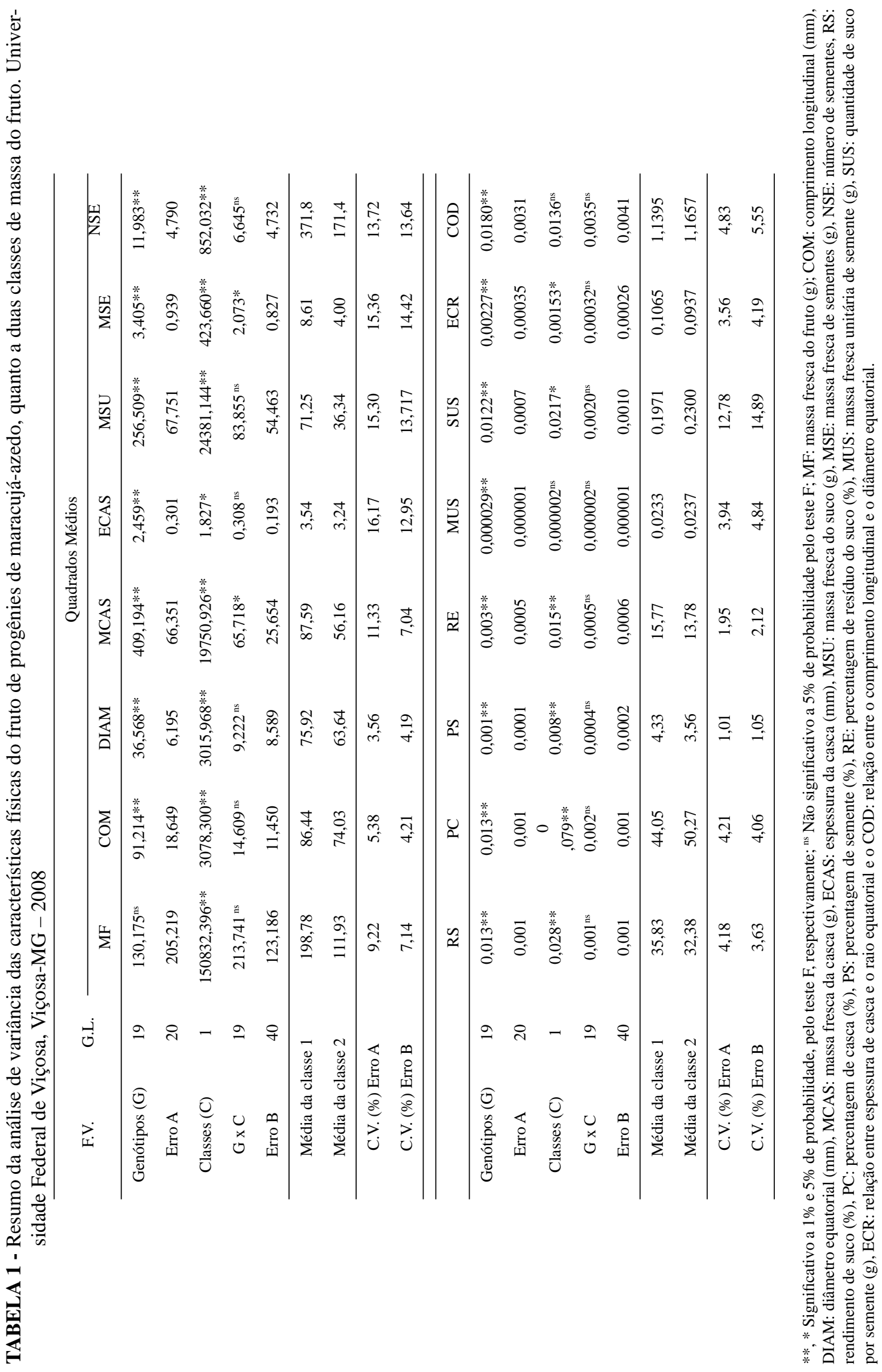




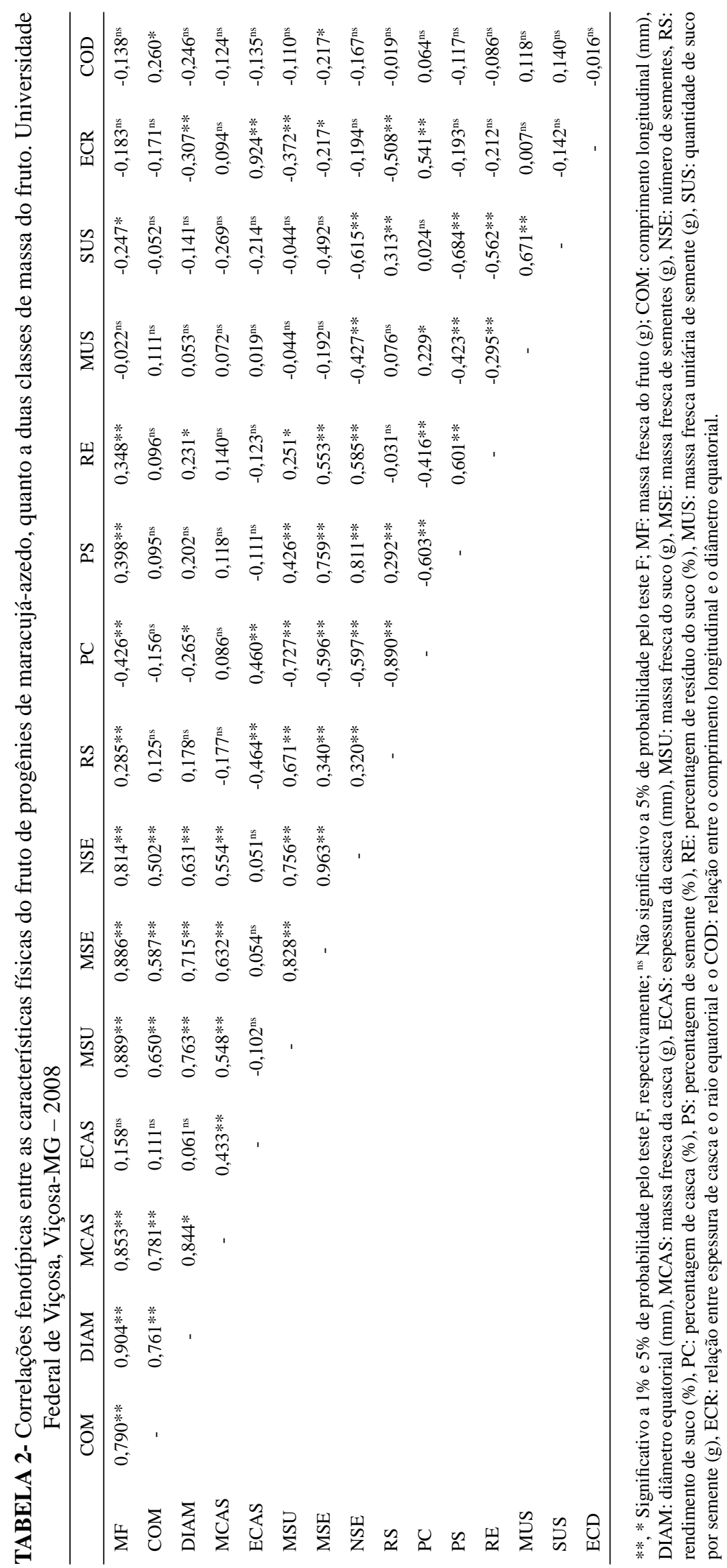

Rev. Bras. Frutic., Jaboticabal - SP, v. 31, n. 4, p. 1102-1110, Dezembro 2009 


\section{CONCLUSÕES}

1-A espessura da casca varia com a massa do fruto, de modo que a avaliação da espessura da casca em frutos de diferentes massas pode provocar equívocos na avaliação de progênies.

2-O diâmetro equatorial do fruto apresentou maior correlação com a massa fresca do fruto, quando comparado ao comprimento longitudinal, indicando a viabilidade de seleção indireta de progênies com maior massa do fruto pela avaliação do diâmetro.

\section{REFERÊNCIAS}

AGRIANUAL: anuário estatístico da agricultura brasileira. Maracujá: produção brasileira. São Paulo: FNP Consultoria e Comércio, 2008. p. 383-388.

AKAMINE, E.K.; GIROLAMI, G. Pollinattion and fruit set in the yellow passion fruit. Honolulu: University of Hawaii, 1959. 44p.

AKAMINE, E.K.; GIROLAMI, G. Problems in fruit set in yellow passion fruit. Hawaii Farm Science, Honolulu, v. 5, n. 4, p. 3-5, 1957.

AKAMINE, E.M.; ARAGAKI, M.; BEAUMONT, J.H.; BOWERS, F.A.I.; HAMILTON, R.A.; NISHIDA, T.; SHERMAN, G.D.; SHOJI, K.; STOREY, W.B.; MARTINEZ, A.P.; YEE, W.Y.J.; ONSDORFF, T.; SHAN, T.N. Passion fruit culture in Hawaii. Hawaii: University of Hawaii, 1974. 35p. (Circular, 345)

ALBUQUERQUE, A.S.; BRUCKNER, C.H.; CRUZ, C.D.; CASALI, V.W.D.; ARAÚJO, R. da C.; MOREIRA, A.E.; SOUZA, J.A. de. Possibilidade de seleção indireta para peso do fruto e rendimento em polpa em maracujá (Passiflora edulis Sims). In: CONGRESSO BRASILEIRO DE FRUTICULTURA, 17., 2002, Belém. Anais... Belém: Embrapa, 2002. CD-ROM.

ALEXANDRE, R.S.; WAGNER JÚNIOR, A.; NEGREIROS, J.R.S.; PARIZOTTO, A.; BRUCKNER, C.H. Germinação de sementes de genótipos de maracujazeiro. Pesquisa Agropecuária Brasileira, Brasília, v.39, n.12, p. 1239-1245, 2004.
ARAÚJO, C.M.; GAVA, A.J.; ROBBS, P.G.; NEVES, J.F.; MAIA, P.C.B. Características industriais do maracujá (Passiflora edulis var. flavicarpa) e maturação do fruto. Pesquisa Agropecuária Brasileira, Brasília, v. 9, n. 1, p. 65-69, 1974.

ATAÍDE, E.M.; RUGGIERO, C.; OLIVEIRA, J.C. de; RODRIGUES, J.D.; BARBOSA, J.C. Efeito de giberelina $\left(\mathrm{GA}_{3}\right)$ e do bioestimulante 'Stimulate' na indução floral e produtividade do maracujazeiroamarelo em condições de safra normal. Revista Brasileira de Fruticultura, Jaboticabal, v. 28, n. 3, p. 343-346, 2006.

AULAR, J.; RUGGIERO, C.; DURIGAN, J.F. Influência da idade na colheita sobre as características dos frutos e do suco, de maracujá-amarelo. Revista Brasileira de Fruticultura, Jaboticabal, v. 22, n. especial, p. 6-8, 2000.

BATISTA, A.D.; JUNQUEIRA, N.T.V.; JUNQUEIRA, K.P.; LAGE, D.A. da C.; ALENCAR, C.M.; COSTA, D.G.P. da; REZENDE, L.N. Características físico-químicas de frutos de cultivares de maracujazeiro-azedo (Passiflora edulis f. flavicarpa) cultivadas no Distrito Federal. In: REUNIÃO TÉCNICA DE PESQUISAS EM MARACUJAZEIRO, 4., 2005, Planaltina. Anais... Planaltina: Embrapa, 2005. p. $132-136$.

BRUCKNER, C.H.; MELETTI, L.M.M.; OTONI, W.C.; ZERBINI JÚNIOR, F.M. Maracujazeiro. In: BRUCKNER, C.H. (Ed.). Melhoramento de fruteiras tropicais. Viçosa: UFV, 2002. p. 373-409.

CARVALHO, A.J.C. de; MARTINS, D.P.; MONNERAT, P.H.; BERNADO, S. Adubação nitrogenada e irrigação no maracujazeiro-amarelo. I. Produtividade e qualidade dos frutos. Pesquisa Agropecuária Brasileira, Brasília, v. 35, n. 6, p. 1101-1108, 2000.

CRUZ, C.D. Programa GENES - versão Windows: Aplicativo computacional em genética e estatística (versão 2006). Viçosa: UFV, 2001. 642p.

CRUZ, C.D.; REGAZZI, A.J.; CARNEIRO, P.C.S. Modelos biométricos aplicados ao melhoramento genético. Viçosa: UFV, 2004. v.1, 480 p. 
FALEIRO, F.G.; JUNQUEIRA, N.T.V.; BRAGA, M.F. Germoplasma e melhoramento genético do maracujazeiro: desafios da pesquisa. In: FALEIRO, F.G.; JUNQUEIRA, N.T. V.; BRAGA, M.F. (Eds.). Maracujá: germoplasma e melhoramento genético. Planaltina: Embrapa Cerrados, 2005. p. 187-210.

FARIAS, M.A.A.; FARIA, G.A.; CUNHA, M.A.P. da; PEIXOTO, C.P.; SOUSA, J.S. Caracterização física e química de frutos de maracujá-amarelo de ciclos de seleção massal estratificada e de populações regionais. Magistra, Cruz das Almas, v. 17, n. 2, p. 83-87, 2005.

FERREIRA, F.R.; VALLINI, P.C.; RUGGIERO, C.; LAM-SANCHEZ, A. Correlações fenotípicas entre diversas características do fruto do maracujá-amarelo (Passiflora edulis flavicarpa). In: CONGRESSO BRASILEIRO DE FRUTICULTURA, 3., 1975, Rio de Janeiro. Anais... Rio de Janeiro: Universidade Federal Rural do Rio de Janeiro, 1975. p. 481-489.

GONÇALVES, G.M.; VIANA, A.P.; BEZERRA NETO, F.V.; PEREIRA, M.G.; PEREIRA, T.N.S. Seleção e herdabilidade na predição de ganhos genéticos em maracujá-amarelo. Pesquisa Agropecuária Brasileira, Brasília, v.42, n.2, p.193-198, 2007.

HAENDLER, L. La passifora: as composition chimique et ses possibilités de transformation. Fruits, Paris, v. 20, n. 5, p. 235-245, 1965.

LIPITOA, S.; ROBERTSON, G.L. The enzimatic extraction of juice from yellow passion fruit pulp. Tropical Science, West Sussex, v. 19, p. 105-112, 1977.

MELETTI, L.M.M.; SOARES-SCOTT, M.D.; PINTO-MAGLIO, C.A.F.; MARTINS, F.P. Caracterização de germoplasma de maracujazeiro (Passiflora sp). Revista Brasileira de Fruticultura, Jaboticabal, v. 14, n. 2, p. 157-162, 1992.

NASCIMENTO, T.B. do; RAMOS, J.D.; MENEZES, J.B. Características físicas do maracujá-amarelo produzido em diferentes épocas. Pesquisa Agropecuária Brasileira, Brasília, v. 34, n. 12, p. 2353-2358, 1999.
NASCIMENTO, W.M.O. do; TOMÉ, A.T.; OLIVEIRA, M. do S.P. de; MULLER, C.H.; CARVALHO, J.E.U. de. Seleção de progênies de maracujazeiro-amarelo (Passiflora edulis f. flavicarpa) quanto à qualidade de frutos. Revista Brasileira de Fruticultura, Jaboticabal, v. 25, n. 1, p. 186-188, 2003.

NEGREIROS, J.R. da S.; ÁlVARES, V. de S.; BRUCKNER, C.H.; MORGADO, M.A.D.; CRUZ, C.D. Relação entre características físicas e o rendimento de polpa de maracujá-amarelo. Revista Brasileira de Fruticultura, Jaboticabal, v. 29, n. 3, p. 540-545, 2007.

PIMENTEL, L.D.; STENZEL, N.M.C.; CRUZ, C.D.; BRUCKNER, C.H. Épocas de avaliação da produtividade em maracujazeiro visando à seleção precoce. Pesquisa Agropecuária Brasileira, Brasília, 2008. No prelo

SANTOS, C.E.M. dos; PISSIONI, L.L.M.; MORGADO, M.A.D.; CRUZ, C.D.; BRUCKNER, C.H. Estratégias de seleção em progênies de maracujazeiro-amarelo quanto ao vigor e incidência de verrugose. Revista Brasileira de Fruticultura, Jaboticabal, v. 30, n. 2, p. 444-449, 2008.

SENTER, S.D.; RAYNE, J.A.; KNIGHT, R.J.; AMIS, A.A. Yield and quality of juice from passion fruit (Passiflora edulis), Maypops (P. incarnata) and tetraploid passion fruit hybrids ( $P$. edulis $\mathrm{x} P$. incarnata). Journal of the Science of Food and Agriculture, London, v. 62, n. 1, p. 67-70, 1993.

SJOSTROM, G.; ROSA, J.F.L. Estudos sobre as características físicas e composição química do maracujá-amarelo, Passiflora edulis f. flavicarpa Deg. Cultivado no município de Entre-Rios, Bahia. In: CONGRESSO BRASILEIRO DE FRUTICULTURA, 4., Salvador, 1977. Anais... p. 265-273.

VIANA, A.P.; PEREIRA, T.N.S.; PEREIRA, M.G.; AMARAL JÚNIOR, A.T. do; SOUZA, M.M. de; MALDONADO, J.F.M. Parâmetros genéticos em populações de maracujazeiro-amarelo. Revista Ceres, Viçosa, v. 51, n. 297, p. 545-555, 2004. 